\title{
Surgery of Breast Cancer Brain Metastasis at Joliot Curie Cancer Institute: About 4 Cases and Review of the Literature
}

Sidy KA ${ }^{1^{*}}$, Ibrahima Tine ${ }^{2}$, Jaafar Thiam ${ }^{1}$, Maimouna Mane ${ }^{1}$, Doudou Diouf ${ }^{1}$, Mamadou Moustapha Dieng $^{1}$, Pape Macoumba Gaye ${ }^{1}$, Momar Code Ba $^{3}$ and Ahmadou Dem ${ }^{1}$

${ }^{1}$ Joliot Curie Cancer Institute, Cheikh Anta Diop University, Senegal

${ }^{2}$ Neurosurgery Unit, Hopital Principal de Dakar, Senegalese army teaching hospital, Senegal

${ }^{3}$ Neurosurgery Unit, Universitary Hospital of Fann, Dakar, Senegal

*Corresponding author: Sidy KA, Joliot Curie Cancer Institute, Cheikh Anta Diop University, Senegal, Tel: +221338250530; E-mail: sidy.ka@ucad.edu.sn Received date: September 04, 2017; Accepted date: September 28, 2017; Published date: October 03, 2017

Copyright: @ 2017 Sidy KA, et al. This is an open-access article distributed under the terms of the Creative Commons Attribution License, which permits unrestricted use, distribution, and reproduction in any medium, provided the original author and source are credited.

\begin{abstract}
To describe the place of surgery in therapeutic management of breast cancer brain metastasis at Joliot Curie Cancer Institute according to 4 cases. Age at diagnosis was 31, 48, 57 and 63 years. Patients were stage 2 and 3. Molecular were triple negative in 1 case, HER2 positive in 1 case and hormone positive in 2 cases. The median delay of brain metastasis occurrence was 20 months. Neoadjuvant radiotherapy was performed for 1 patient. Surgery of metastasis was complete for 1 patient and partial for 3 patients. No patient had adjuvant whole brain radiotherapy. The average survival time was 13 months.
\end{abstract}

Keywords: Breast; Brain; Metastasis; Surgery; Radiotherapy; Survival

\section{Introduction}

The occurrence of cerebral metastasis in breast cancer is a major prognostic and therapeutic turning point [1,2]. Surgery plays an important role in a multidisciplinary approch with radiotherapy and medical treatments [3,4]. At Joliot Cancer Institute, external radiotherapy is the main treatment for cerebral metastases. Surgery has been proposed to some patients. The objective of this study was to evaluate the results of cerebral metastasis surgery in breast cancers in 3 patients.

\section{Cases Presentation}

\section{Observation 1}

Patient of 48 years, having presented a left breast T3N1M0 carcinoma triple negative. She received neo-adjuvant chemotherapy followed and mastectomy with axillary dissection followed by external radiotherapy on the chest wall. She presented 6 months after the end of treatment a persistent headache. CT of the brain showed a single large frontal secondary tumor (Figure 1). She underwent brain radiation therapy. Post radiation therapy CT showed lesions filled with necrosis. Radiotherapy was followed by surgery of the metastasis. It consisted of necrosis drainage. She felt better without headache. She died 6 months after surgery after temporal relapse.

\section{Observation 2}

Patient of 57 years, I geste I pare, having presented a right breast cancer classified T2N1M0, with positive oestrogene and progesterone receptors. She received neo-adjuvant chemotherapy and mastectomy with axillary dissection followed by external radiotherapy on the chest wall. She presented 24 months after the end of treatment a sudden hemiplegia. Brain CT showed a single isolated frontal $5 \mathrm{~cm}$ of diameter secondary tumor. She underwent surgery of metastasis and had complete histologic and radiologic response (Figure 2).

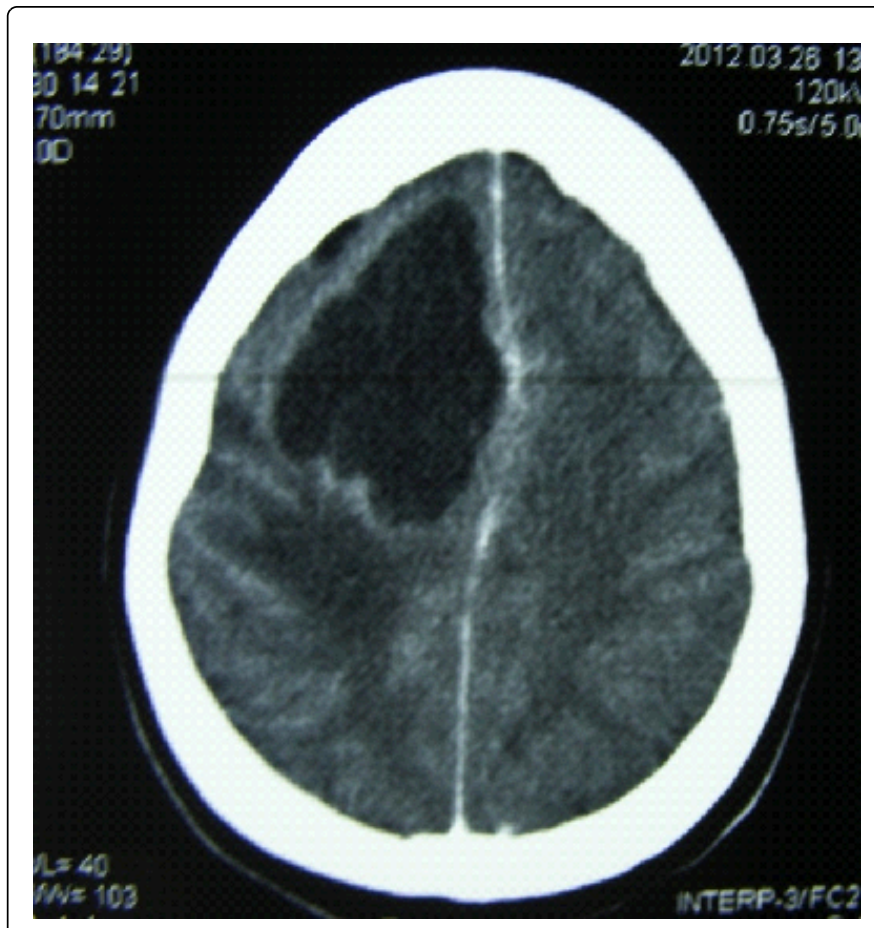

Figure 1: Single large frontal metastasis.

She recovered the motor function at $60 \%$. Adjuvant radiotherapy was not performed. She died 18 months after surgery after a recurrence of the brain tumor (Table 1). 
Citation: Sidy KA,Tine I, Thiam J, Mane M, Diouf D, et al. (2017) Surgery of Breast Cancer Brain Metastasis at Joliot Curie Cancer Institute: About 4 Cases and Review of the Literature. J Tum Res Rep 2: 114.

Page 2 of 4

\begin{tabular}{|l|l|l|l|l|l|l|l|}
\hline & Age (years) & Stage & Molecular subtype & Delay of occurrence (months) & $\begin{array}{l}\text { Location } \\
\text { metastasis }\end{array}$ & Type of surgery & $\begin{array}{l}\text { Survival } \\
\text { (month) }\end{array}$ \\
\hline Patient 1 & 48 & II & triple negative & 6 & frontal & drainage & 6 \\
\hline Patient 2 & 57 & II & $\begin{array}{l}\text { hormone receptors } \\
\text { positive }\end{array}$ & 24 & frontal & complete & 18 \\
\hline Patient 3 & 63 & II & $\begin{array}{l}\text { hormone receptors } \\
\text { positive }\end{array}$ & 47 & cerebellar & complete & 6 \\
\hline Patient 4 & 31 & III & her 2 positive & 5 & posterior & partial & 21 \\
\hline
\end{tabular}

Table 1: Summary Table.

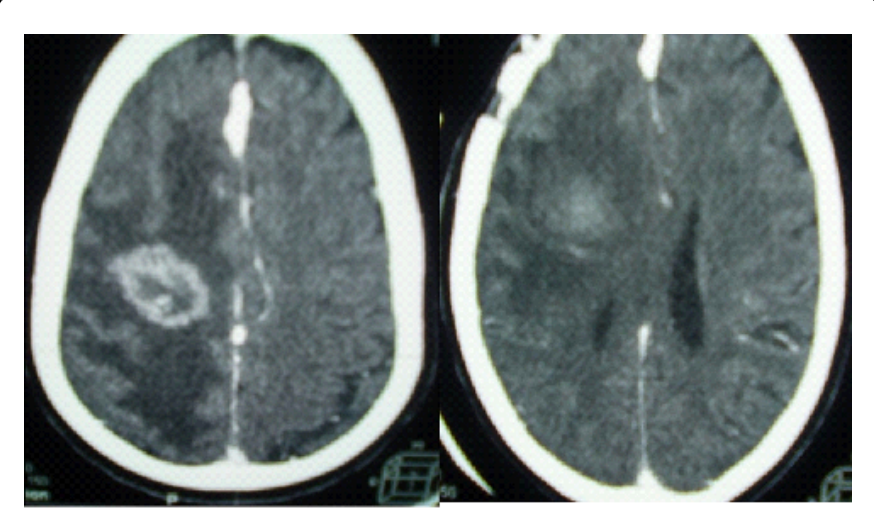

Figure 2: Brain metastasis before and after surgery.

\section{Observation 3}

Patient 63 years old, having presented an invasive right T2N1M0 breast carcinoma of non-specific type with positive hormonal receptors and HER 2 negative. She received neo-adjuvant chemotherapy followed by a mastectomy with axillary dissection and radiotherapy on the chest wall. She presented 47 months after the end of treatment headache and balance disorders. Central nervous CT showed a single 4 $\mathrm{cm}$ cerebellar metastasis filled with necrosis (Figure 3). She has undergone surgery to respect the metastasis (Figure 4). She recovered balance and all symptoms disappeared. She died 6 months after surgery.

\section{Observation 4}

It was about a 31 years old patient treated for left breast carcinoma T4DN0M0. She was estrogen receptor positive and HER2 positive. She benefit from 2 courses of chemotherapy with a first line of CMF (cyclophosphamid, Methotrexate, Fluorouracile) and a second line of AC (Adriamycin, Cyclophosfamid) and then mastectomy followed by radiotherapy and hormone therapy. After 5 month of tamoxifen she claims of headache. Clinical examination showed intracranial hypertension and motion disorders while MRI showed a posterior cerebral single metastatic lesion. She underwent non optimal surgery of the metastasis and recover motion and behavior. Secondary lesion of the brain relapsed 21 months after and death occurred.

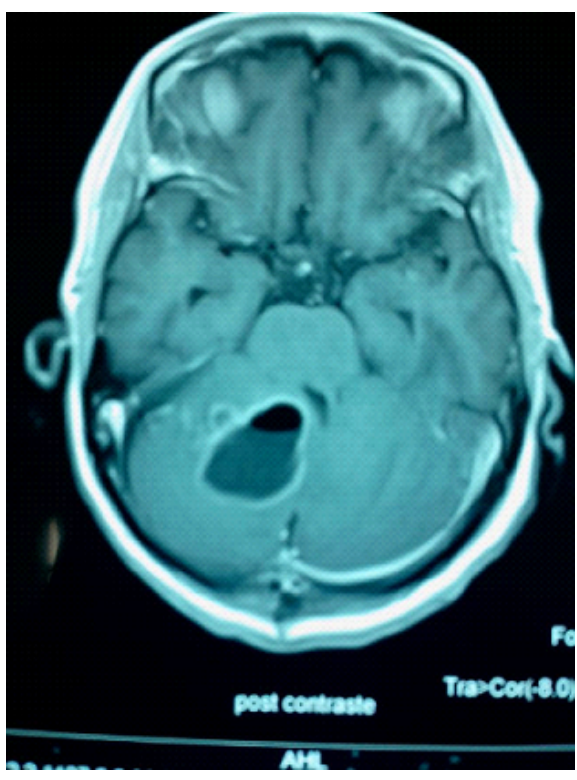

Figure 3: Single $4 \mathrm{~cm}$ cerebellar metastasis filled with necrosis.

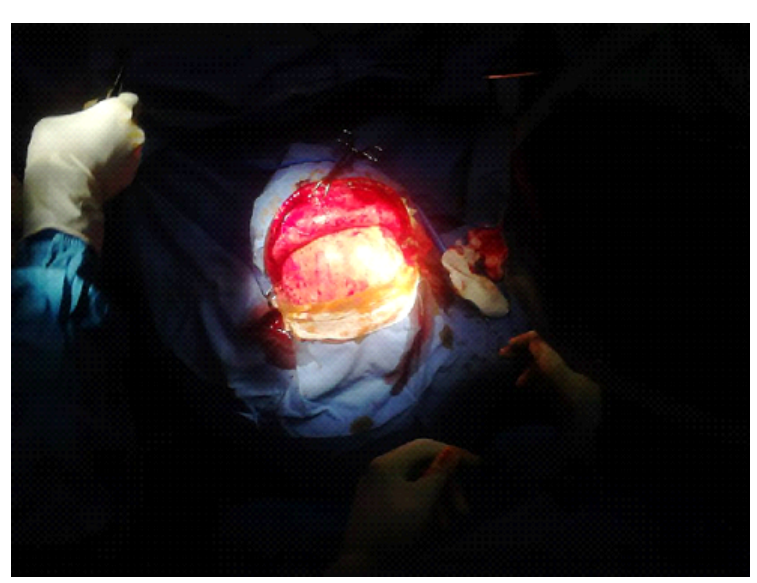

Figure 4: Surgical way for cerebellar metastasis. 


\section{Comments}

Cerebral metastases occurred in the history of breast cancer in $15 \%$ of cases. It represents the fourth most common secondary tumor during breast cancer natural history. Breast cancer is the second leading cause of cerebral metastases in women after lung cancers [2]. The first autopsy series in African people compared with recent literature showed different causes of brain metastasis. Choriocarcinoma was the first causes of brain metastasis in Nigeria. Since this time the improvement of chemotherapy raised the prognosis this cancer [5]. Racial disparities in breast cancer incidence does not seem to be correlated with brain metastasis distribution [6]. At Joliot Curie Cancer Institute, breast cancer is the leading cause of cerebral metastasis followed by lung cancers and soft tissue sarcomas [7].

Risk factors of cerebral metastases in breast cancers are stage, hormonal status and molecular profile. Breast cancer risk factors like number of parities and duration of breastfeeding related to hormonal status do not seem to be implicated in brain metastasis occurrence [8].

The main factors are advanced stages, BRCA1 mutated patients, triple-negative cancers and cancers expressing oncoprotein HER2 [9].

According to Paget theory of "seed and soil" since 1889, the brain seems to be a good field for Cerb2 overexpressed breast cancer [10]. The management of patients with metastatic disease at time of diagnosis showed a poor prognosis. The management of these patients is systemic and cerebral [11].

The median time of occurrence is shorter than the delay found in the literature [12].

Headache, epilepsy, intracranial hypertension and seizure are the most frequent symptoms. The peripheral signs are related to the sites of metastasis. The most frequent is hemiplegia $[13,14]$. The severities of signs are related to number and size of metastasis [15]. The size, location and number of metastases are well appreciated in Imaging. Computed tomography and magnetic resonance imagery (MRI) are the main modalities. MRI has a better sensitivity [16].

Invasive adenocarcinoma with non-specific type is the most frequent histological type. HER2 cancers develop cerebral metastases in at least $50 \%$ of cases. Anti HER 2 treatment improves the prognosis. Triple-negative breast cancer is the second in terms of frequency after HER2 subtype. Secondary lesions for triple negative cancers are more systemic than cerebral $[17,18]$.

Treatments are hierarchized. Corticosteroids are mandatory. Symptoms are better controlled before surgery and radiotherapy [19]. Surgery is the main curative treatment. The indications depend on the benefit/risk ratio. Respectability depends on the number, location and size of the tumors. Temporal tumors have better prognostic. Surgery is optimal for lesions 30 to $40 \mathrm{~mm}$ away from functional areas. Clears surgical margins are recommended and surgery need to be followed by pan encephalic radiotherapy $[20,21]$. The modalities of radiotherapy have evolved over time. The exclusive radiotherapy of the encephalon is dedicated only for multiple lesions. Between 1 and 4 lesions less than $30 \mathrm{~mm}$, radiosurgery is less deleterious than surgery [22,23].

Complications of surgical treatment are frequent. They are related to edema, functional parenchymal resection and decubitus $[24,25]$. The contribution of new technologies in surgery including neuronavigation and intraoperative monitoring provide surgical precision and safety [26]. The first month post-operative period is marked by at least $6 \%$ of major neurological complications in the best centers. The prognosis depends on the quality of the resection, the sequelae and the molecular profile of breast cancer. Survival is around 1 month without treatment, 2 months under corticotherapy and is improved from 60 to $80 \%$ after total irradiation [27]. Radiosurgery provides 95\% local control but does not improve prognosis without surgery. An increase of lesion size can be observed on CT and MRI while biopsies shows for the same cases tumors necrosis $[28,29]$. Chemotherapy reduces the size of metastasis. Its prognostic role is not important. The regimens based on telozolomide, cysplatin, etoposide and capecitabine are recommended [30,31]. HER2 patients benefit from the addition of lapatinib and trastuzumab. The experience of intratechal trastuzumab does not seem very conclusive. The combination of chemotherapy and target therapies is better than targeted therapies alone [15,32,33]. Prevention of cerebral metastases is the main strategy to reduce mortality associated with breast cancer brain metastasis. Tailored treatment according to the molecular profile particularly HER 2 overexpressed patients is the main axis of this prevention [34].

\section{Conclusion}

Surgery in combination with radiotherapy and targeted therapies is the most effective treatment of breast cancer cerebral metastases. Isolated lesions have better prognosis. Prevention through screening programs and the strengthening of diagnostic rules, particularly in the determination of the biological profile of cancers, can improve the prognosis in disadvantaged centers.

\section{Ethics Approval and Consent to Participate}

This article respects our institution's ethics committee

\section{Competing Interest}

There are no competing interests.

\section{Funding}

None

\section{Authors' Contributions}

Sidy Ka and Ibrahima Tine reported and analysed data. Ahmadou Dem controlled the quality. All authors read and approved the final manuscript.

\section{Acknowledgement}

None

\section{References}

1. Petit $\mathrm{T}$ (2010) Métastases cérébrales et cancer du sein. La lettre du cancérologue 19: 134-137.

2. Gavrilovic IT, Posner JB (2005) Brain metastases: epidemiology and physiopathology. J Neurooncol 75: 5-14.

3. Chargari C, Idrissi HR, Pierga JY (2010) Radiothérapie encéphalique totale et adjonction concomitante de Trastuzumab pour des métastases cérébrales d'un carcinome mammaire surexprimant HER2: expérience de linstitut curie. Cancer/Radiother 14: 584-665.

4. Kirova YM, Chargari C, Mazeron JJ (2011) Métastases cérébrales multiples d'un cancer du sein et leur prise en charge en radiothérapie : quelle est l'attitude thérapeutique la mieux adaptée ? Bull Cancer 98: 409-415. 
Citation: Sidy KA,Tine I, Thiam J, Mane M, Diouf D, et al. (2017) Surgery of Breast Cancer Brain Metastasis at Joliot Curie Cancer Institute: About 4 Cases and Review of the Literature. J Tum Res Rep 2: 114.

Page 4 of 4

5. Adoloye A, Odeku EL (1969) Metastatic neoplasms of the brain in Nigeria. Br J Cancer 23: 340-348.

6. Schootman M, Jeffe DB, Gillanders WE (2009) Racial disparities in the development of breast cancer metastasis among older women : a multilevel study. Cancer 115: 731-740.

7. Dem A, Traore B, Dieng MM, Diop PS (2008) Gynnaecoloical and breast cancers at the Dakar Cancer Institute. CERF/Sante 18: 25-29.

8. Babalou A (2017) The Association of Parity and Breastfeeding with Breast Cancer : A Review. Health Sci J 11: 1

9. Qi Wu, Juanjuan Li, Shan Zhu, Juan Wu (2017) Breast cancer subtypes predict the preferential site of distant metastases: a SEER based study. Oncotarget 8: 27990-27996.

10. Paget S (1889) The distribution of secondary growths in cancer of breast Lancet 133: 571-603.

11. Gachet J, Giroux J, Girre V (2011) Métastases cérébrales dans les cancers du sein. Epidémiologie et histoire naturelle. Expérience de l'Institut Curie à travers deux études : les patientes HER2- de moins de 65 ans et les patientes de plus de 65 ans. Bull Cancer 98: 357-369.

12. Leone JP, Lee AV, Brufsky AM (2015) Prognostic factors and survival of patients with brain metastasis from breast cancer who underwent craniotomy. Cancer Med 4: 989-994.

13. Dupont S (2008) Epilepsie et tumeurs cérébrales. Rev Neurol 164 517-522.

14. Hamilton W, Kernick D (2007) Clinical features of primary brain tumours : a case-control study using electronic primary care records. Br J Gen Pract 57: 695-699.

15. Bennett EE, 15. Angelov L, 15. Vogelbaum MA, 15. Barnett GH (2017) The prognostic role of tumor volume in the outcome of patients with single brain metastasis after stereotactic radiosurgery. World Neurosurg. 104: 229-238.

16. Rochette-Paris M, Kremer S, Taillandier L (2004) Tumeurs cranioencéphaliques. Techniques d'imagerie et sémiologie. Encycl Med Chir, Radiologie 1: 604-620.

17. Metro G, Fabi A (2012) New target therapies for brain metastases from breast cancer. Curr Cancer Drug Targets. 12: 310-317.

18. Gong Y, 18. Liu YR, 18. Ji P, 18. Hu X, 18. Shao ZM (2017) Impact of molecular subtypes on metastatic breast cancer patients: a SEER population-based study. $18 . \quad$ Sci Rep 7: 45411.

19. Borgelt B, Geller R, Kramer S (1980) The palliation of brain metastases : Final results of the first two studies of Radiation Therapy Oncology Group. Int J Radiat Oncol Biol Phys 6: 1-9.

20. Tsao M. N, Lloyd N, Wong R.K (2005) Clinical practice guidelines on the optimum radio-therapeutic management of brain metastases. BMC Cancer 5-34.
21. Guillamo JS, Emery E, Busson A, Lechap-Zalcman E (2008) Current management of brain metastasis. Rev Neurol 164: 560-568.

22. Patchell RA, Tibbs PA, Walsh JW (1990) A randomized trial of surgery in the treatment of single metastases to the brain. N Eng J Med 322: 494-500.

23. Tsao MN, Lloyd NS, Wong RK, Rakovitch E, Chow E, et al (2005) Radiotherapeutic management of brain metastases: a systematic review and meta-analysis. Cancer Treat Rev 31: 256-73.

24. Chami S, Mekkit F (2010) Les métastases cérébrales:profil épidémiologique et résultats thérapeutiques, à propos d'une série de patients traités dans un service de radiothérapie à Alger. Cancer/ Radiother 14: 584-665

25. Gaspar L, Scott C, Rottman M (1997) Recursive partitioning analysis (RPA) of prognostic factors in three Radiation Therapy Oncology Group (RTOG) brain metastases trials. Int J Radiat Oncol Biol Phys 37: 745-751.

26. Wadley J, Dorward N, Kitchen N and Thomas D (1999) Pre-operative planning and intra-operative guidance in modern neurosurgery: a review of 300 cases. Ann R Coll Surg Engl 81: 217-225.

27. Raskin R, Weiss SR, Manning JJ (1971) Survival after surgical excision of single metastatic brain tumors. Am J Roentgenol Radium Ther Nucl Med 11: 323-328.

28. Feuvret L, Germain I, Cornu P (1998) Intérêt de la radiothérapie en conditions stéréotaxiques (radiochirurgie) des métastases cérébrales: expérience et résultats du groupe hospitalier Pitié-Salpetrière. Cancer/ Radiother 2: 272-281.

29. Menoux I, Armspach JP, Noel G, Antoni D (2016) Imaging methods used in the differential diagnosis between brain tumour relapse and radiation necrosis after stereotactic radiosurgery of brain metastases: literature review. Cancer Radiother 20: 837-845.

30. Rosner D, D M, Nemoto T (1986) Chemotherapy induces regression of brain metastases in breast carcinoma. Cancer 58: 832-839.

31. Walbert T, Gilbert MR (2009) The role of chemotherapy in the treatment of patients with brain metastases from solid tumors. Int J Clin Oncol 14: 299-306.

32. Teplinsky E, Esteva F (2015) Systemic Therapy for HER2-Positive Central Nervous System Disease: Where We Are and Where Do We Go From Here? Curr Oncol Rep 17: 46.

33. Larsen PB, Kümler I, Nielsen DL (2013) A systematic review of trastuzumab and lapatinib in the treatment of women with brain metastases from HER2-positive breast cancer. Cancer Treat Rev 39: 720-727.

34. Le Tourneau C (2011) Stratégies de prévention des métastases cérébrales dans les cancers du sein HER2+. Bull Cancer 98: 445-449. 